\title{
Netizens' Responses to a Famous Indonesian Youtuber Video of Changing Religious Beliefs on YouTube Social Media
}

\author{
Lala Nur Pratiwi*, Hafied Cangara \\ Faculty of Social and Political Sciences \\ Hasanuddin University Makassar \\ Makassar, Indonesia \\ *lalapratiwi23@gmail.com, cangara_hafied@yahoo.com
}

\begin{abstract}
The ability of a new media user is seen as a new way of communicating; netizens now have the power to respond directly to information received through social media. This study discusses the response of netizens to videos of Deddy Corbuzier' religious converts on YouTube social media. This study aims to determine the attention, understanding, and acceptance of netizens of Deddy Corbuzier's video. This study uses a qualitative approach with qualitative content analysis methods, namely analysing data in the form of comments given by netizens through symbols of like or dislike and comments. Based on the results of the study, it was found: 1) The attention of netizens in responding to Deddy Corbuzier's conversion video in the form of a response to a symbol of like or dislike and comments, 2) The netizens' perception towards the video consists of positive, negative, and neutral comments, 3) Netizens' acceptance in the form of desire to change for the better is to become more obedient, steadfastness, convert and accept Deddy's decision to convert, 4) Netizens argue with other netizens regarding the video of Deddy Corbuzier's religious converts.
\end{abstract}

Keywords—respons, religious converts, YouTube

\section{INTRODUCTION}

The presence of new media has dismissed the belief that media are power of information production and distribution. New media offers a way to find, publish, store, and consume information in ways that were never done. All this time, the conventional media as the sole authority of information places the audience as passive consumers. The audience does not have the power to control the content that presented by conventional media, and the position of the audience is often only used as the target of various information [1]. However, the presence of new media has presented a different experience and has the potential to change the perception of audiences as passive consumers.

The ability of audience of new media users or citizens of the internet are seen as a new way of communicating, citizens of the internet have the power to produce messages as previously done by conventional media, even citizens of the internet can use new media at relatively low cost. Citizens of the internet are not only free to produce and spread messages but allowed to choose information according to their interests and needs. This information can be obtained easily without any time limit as presented in conventional media. The citizens of the internet are no longer just the objects that exposed to information, but also actively participate because new media provide opportunities for everyone to be involved in direct interaction [1].

YouTube is one of the many social media that is quite popular. Based on the latest data from We Are Social in 2020, it is stated that there are 175.4 million internet users in Indonesia. Based on Indonesia's total population of 272.1 million, it means that $64 \%$ of Indonesians have accessed the internet. As for YouTube users in Indonesia, as many as $88 \%$ of the total population make YouTube the most used social media in Indonesia, followed by WhatsApp users with $84 \%$ of the population [1].

This fact indicates that YouTube is the preferred social media for many citizens of the internet to obtain and share information. YouTube is not only used as a medium for obtaining information but YouTube users can use it to present information and disseminate it. YouTube with its mass video sharing feature is able to form a view of an object [2].

The various themes can be used by YouTube users to start their personal channels, so it is not surprising that YouTube is now used as a media for Islamic speech because it is considered to have a larger distribution of viewers and from various groups so that the purpose of Islamic speech can be achieved. Online experiments about Islamic speech on YouTube has wrote to look at the way some of the norms of ethical [3].

The converts share personal experiences on YouTube not only to share their life stories but also as a form of preaching. Currently, the issue of religious conversion is an event that is still in the big spotlight for the public and is considered a 
sensational thing especially if it is a public figure who decides to convert to religion.

Religious conversion is a personal matter, everyone has the right to choose and change their beliefs as long as they are not under duress. But when the public still considers that religious conversion to be sensational, during that time the topic of religious conversion can lead to conflict.

The talk show video of Deddy Corbuzier's decision to change the belief that was uploaded on the Hotman Paris Show YouTube channel received the attention of citizens of the internet and invited various comments. The high interest of citizens of the internet to watch indicates citizens' interest in the story of converts.

Unfortunately, the interaction between YouTube users that is realized by writing comments is not longer limited to telling each other's opinions, so that the comments did not have restrictions. Each user can easily write down all the complaints while watching and comments that do not match with the theme that has been discussed in the video.

The reality of the way citizens of the internet comment in the new media is questionable, why does the culture of derogatory comments seem to be something that should be tolerated in the cyber world, especially when realizing that the decision to choose a belief is a personal matter so that comments aimed at insulting the decision of converts to believe in their belief is not ethical to show in public.

To find out this phenomenon requires research that can reach and analyse how a text is produced. One of the researches used to reveal and see the trends in media content is qualitative content analysis. Qualitative content analysis is a method used to examine documents in the form of text, images, symbols, and so on to understand the culture of a particular social context [4].

In knowing the reality of religious beliefs, there is a question how citizens of the internet respond to the phenomenon of converting decisions. Regarding the facts and potential problems that arise, it encourages researchers to conduct research on the response of citizens of the internet of the changes religious beliefs by Deddy Corbuzier on YouTube social media.

Previous research on citizens of the internet response has been carried out, in theirs research entitle "Respon Netizen terhadap Dakwah bi al-Qalam K.H. Muhammad Arifin Ilham di Media Sosial" written by Siti Tarwiah and Uwes Fatoni. The results of this study found that the attention of citizens of the internet in providing responses in the form of emoticons and comments, the understanding of citizens of the internet in the form of positive, negative and un-theme comments, and netizen acceptance in the form of a desire to change for the better. The study also focuses on finding out how citizens of the internet respond in using qualitative content analysis methods. The thing that distinguishes this research is the objective of the study, namely citizens of the internet who respond in the form of comments on videos of conversion of religious beliefs by
Deddy Corbuzier which aired on the YouTube channel Hotman Paris Show.

The aim of this research is to find out how citizens of the internet respond to Deddy Corbuzier's videos on conversion of religious beliefs on the YouTube channel. Theoretically benefits of this research are for the development of communication science insights related to the response of citizens of the internet on social media and qualitative content analysis. Practically, this research is expected to be a reference for future research and can add insight to third audiences using social media, especially when responding in the form of comments.

\section{METHODS}

The research method used is qualitative content analysis. Content analysis begins with coding the terms or the use of relevant words and sentences, which mostly appear in communication media. In providing coding, it is also necessary to note the context in which the term appears. Then do the classification of the coding that has been done. Classification is done by looking at the extent to which the unit of meaning is related to the research objectives. This classification aims to build a category from each classification. Then, the units of meaning and categories are analysed and relationships are sought to find the meaning, meaning, and purpose of the content of the communication. The results of this analysis are then described in the form of a draft report as in general research reports [5].

According to Bungin [5], the content analysis technique includes efforts such as the classification of symbols used in communication, using criteria in classification, and using certain analytical techniques in making predictions. The researcher begins the analysis by using certain symbols, classifying the data with certain criteria and making predictions with certain analytical techniques. The following is a picture of the content analysis technique:

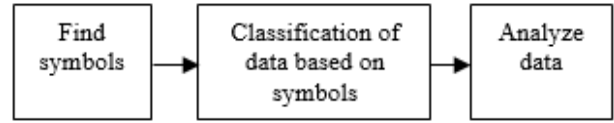

Fig. 1. Content Analysis Technique [5].

\section{RESULTS AND DISCUSSION}

Deddy Corbuzier is well-known as a public figure in entertainment industry of Indonesian. He started his career as a magician in 1999. Currently Deddy is an active presenter on talk show programs and has a personal channel on YouTube. As a public figure, Deddy Corbuzier's personal life did not escape the media coverage, especially when Deddy decided to change his faith and become a convert. The pros and contras of Deddy's decision materialized in the number of viewers and comments left by citizens of the internet when watching Deddy's talk show video on the Hotman Paris Show YouTube channel. 
Citizens' interest in clarifying religious conversions by Deddy Corbuzier is indicated because his figure is well-known as a public figure in Indonesia and the ease of accessing the video on YouTube allows citizens of the internet to watch it. Citizens of the internet consider this to be easier for citizens of the internet to get information related to Deddy's religious conversions than having to watch the news on television. The information broadcast on television has been arranged in such a way according to the run down which every minute has been filled by a certain program slot and there is no repetition of the program when the audience is late to turn on the television. Enjoying this information on YouTube is an alternative because uploaded videos are always stored so that citizens of the internet can access these videos at any time according to the free time that citizens of the internet have. Now, internet became the major source for finding information [6].

Citizens' responses to the video that have been watched as many as 9 million times currently total 6.8 thousand likes, 5.8 thousand dislikes, and 6.9 thousand comments. In the Stimulus-Organism-Response theory, three aspects of response have been explained, namely attention, understanding, and acceptance.

Stimulus-organism-response theory states that the stimulus given to the communicant can be accepted or rejected. Communication can be realized if the communicant pays attention, then the next process the communicant understands. When the communicant is able to process the stimulus given and receive it, there is a willingness to change attitudes. These three things are aspects of the response [7].

Comment toward attitude evaluation, individual entity, are usually called sentiment. Everyone is free to give opinion related with the present opinion on YouTube [8]. The response of citizens of the internet to the video of changing religious beliefs by Deddy on the YouTube channel is further explained through three aspects, namely attention, understanding, and acceptance.

\section{A. The Netizens Attention to Deddy Corbuzier's Conversion of Religious Beliefs on the Hotman Paris Show YouTube Channel}

Attention is a mental process when a series of stimuli becomes prominent in consciousness when other stimuli are weakened [9]. The attention referred to in this study is the mental process of citizens of the internet who consciously give likes or dislikes and comments. Such actions are considered as giving more stimuli, while those who do not leave traces after watching the video are considered to have weak awareness.

Based on the observations of the attention paid by citizens of the internet to Deddy's conversion video, it was noted that 9 million views of the video were watched. This number is the number of citizens of the internet who are interested in seeing Deddy's clarification video, then 6.8 thousand gave likes, 5.8 thousand gave dislike, and 6.9 thousand gave comments. Even though it has been watched as many as 9 million times, not all citizens of the internet show their concern to give a response about their likes or dislikes. This action is normal because the stimulus given to citizens of the internet does not guarantee a large response. Citizens of the internet as an audience have free will to accept and refuse to respond after receiving a stimulus.

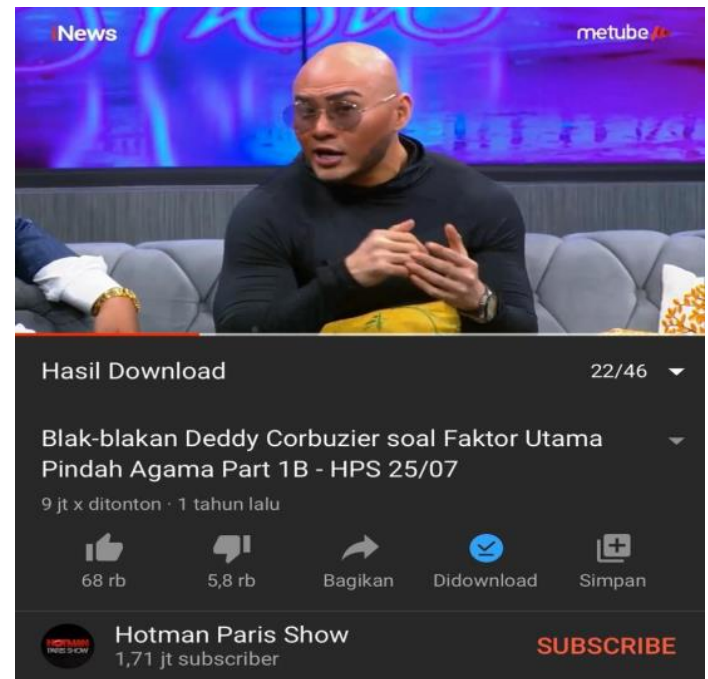

Fig. 2. Talkshow Deddy Corbuzior on channel YouTube Hotman Paris Show.

On social media, the audience can voice their opinion. However, not all social media users are interested in leaving their mark by writing comments, there are also users who are satisfied using social media even though they only see the content presented. For the various types of users, White and Le Cornu [10] divided the internet users as visitors and residents. As visitors, users access certain sites on a whim and never leave traces on the sites that have been accessed. Meanwhile, as a determinant, users consciously spend their time doing social interactions in cyberspace, not just collecting information so that the user's whereabouts can be known.

Attention can come from internal and external. Internally, citizens of the internet pay greater attention to the video by taking the time to provide like and dislike symbols so that writing comments is indicated because the events experienced by Deddy are related to citizens' personal lives. From the findings, it was found that citizens of the internet also wrote down their experiences of converting to Islam. There are also those who say they are still trying to follow Deddy's decision. Meanwhile, from externals, the attention of citizens of the internet arises because of the principle of novelty. New things that are extraordinarily different, will attract citizens' attention to know the latest events.

\section{B. The Netizens Understanding to Deddy Corbuzier's Conversion of Religious Beliefs on the Hotman Paris Show YouTube Channel}

Understanding is the result of thinking, which is a summary of the main characteristics of a reality which is stated in a word [11]. The definition referred to in this study is the result of netizen thinking by understanding the contents of the video and 
then writing down the netizen in the comments column. This understanding is manifested in how citizens of the internet comment. The form of these comments can be positive, negative, or outside of the discussion. This difference is in accordance with how citizens of the internet understand the videos they have watched.

The researcher has mapped various citizens of the internet comments into three groups. The following is the explanation of comments from citizens of the internet regarding the video of Deddy Corbuzier's conversion to religious beliefs.

First, positive comments. The positive comments are meant that written in polite speech and do not vilify the video. citizens of the internet commented on the video clarifying conversions made by Deddy Corbuzier, the sentences written were praise, remarks, to prayers aimed at increasing Deddy's faith after deciding to convert to Islam. These positive comments were indeed written by citizens of the internet who now adhere to the beliefs that Deddy believes in, but this support is also written by citizens of the internet whose trust Deddy has abandoned. The citizens of the internet reluctantly wrote down the religion he believed in and congratulated the public figure who practiced his new faith.

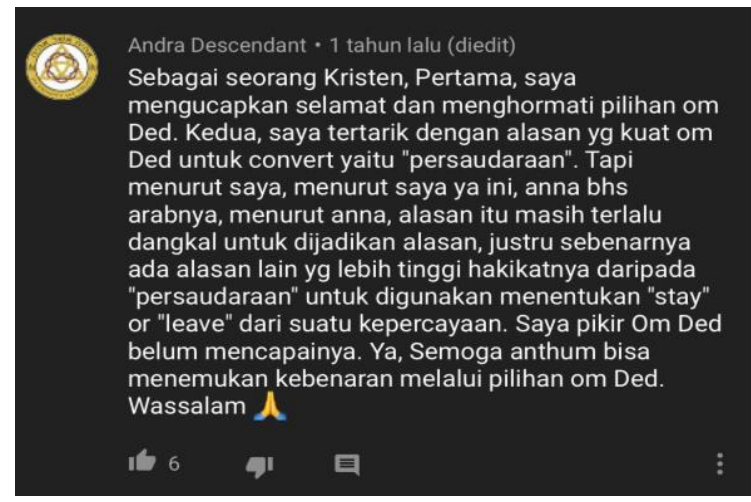

Fig. 3. Positive comment from netizens non muslim.

Second, negative comments. Negative comments are comments that indirectly drop the contents of Deddy's conversion video. These negative comments consist of criticism, insults, and dislikes. citizens of the internet in this category tend to express their comments in harsh to vulgar language. The negative comments given were related to the disapproval of non-Muslims with Deddy's action to change religions. Written sentences filled with insults aimed at Deddy accompanied by bad prayers. As well as accusations against Deddy of convention of religions because there were quite a lot of women being found. There were also those who commented that Deddy was not a good follower of Christian teachings so that he thought he did not deserve to claim to be Christian. Negative comments were not only written by non-Muslim citizens of the internet, but Muslim citizens of the internet also made comments that doubted Deddy's decision to become a Muslim.
The negative comments written by citizens of the internet encourage interactivity between citizens of the internet in the video comment column. The interaction of giving comments led to a comment war between citizens of the internet. The citizens of the internet do not hesitate to write down sentences and use vulgar words to attack each other's comments.

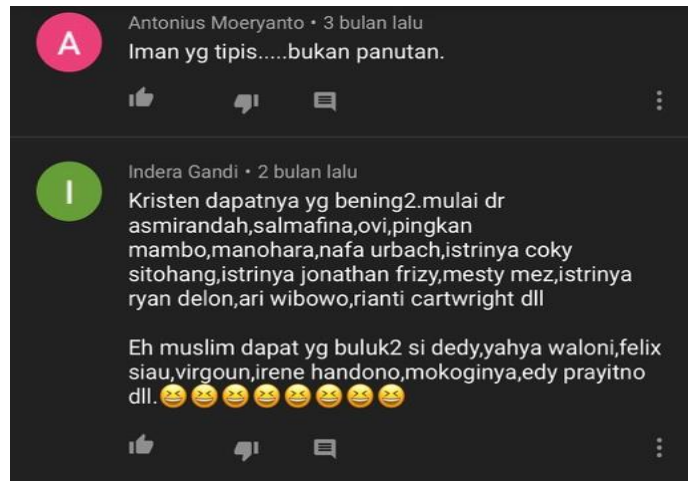

Fig. 4. Netizens insult Deddy’s decision.

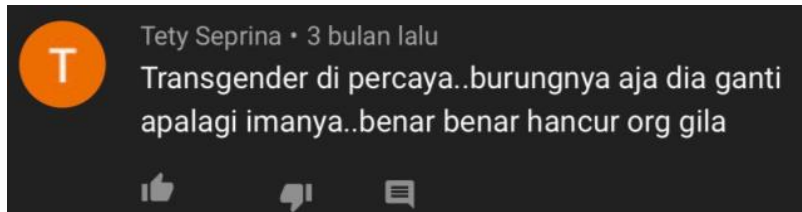

Fig. 5. Negative comment using vulgar words.

Even though other citizens of the internet did not take part in the comment war, their presence can be found by their actions giving a liking symbol to the comments they like to give a symbol of dislike to citizens of the internet comments which they deem contrary to their beliefs. The phenomenon of liking and disliking comments is also an interesting thing for the comments war waged by citizens of the internet who oppose the topic.

Third, neutral comments. Neutral comments are comments from citizens of the internet who do not approve or reject the video. The citizens of the internet actually comment outside the topic being discussed. Generally, such citizens of the internet are often referred to as citizens of the internet who are wrong to focus or fail to focus. The presence of citizens of the internet who comment off-topic is not inferior to citizens of the internet who give negative comments. Previously, many citizens of the internet waged a war of comments on the debate between agreeing and disagreeing with Deddy's actions. The citizens of the internet who are in a neutral position tend to comment on the co-hosts who were present at the talk show Hotman Paris and Deddy Corbuzier. They insulted the co-host who appeared and compared it with other co-hosts, both physically and in behaviour. Not only insulting the co-host, there were also citizens of the internet who also commented outside the topic, namely they made the comments feature on YouTube as an opportunity to communicate with public figures to ask for financial assistance for the problems they were facing. 


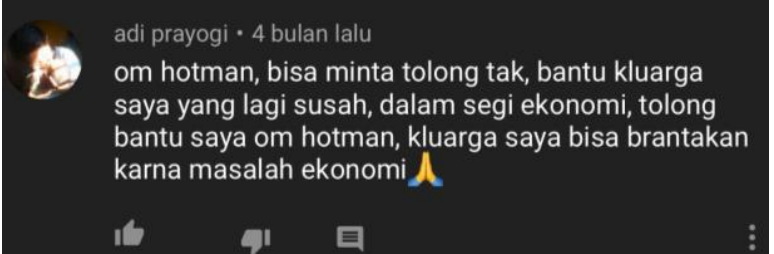

Fig. 6. Netizens focus on their problems.

The comments that are different from the topic may seem strange but the actions of these citizens of the internet are one of the characteristics of the new media that make them different from the previous mainstream media. When compared with the previous media, let alone giving comments outside the topic of conversation, giving suggestions does not seem like an easy thing to do. The presence of new media now makes it easier for every user to interact with anyone using any media.

Based on the research findings, the process of understanding each citizens of the internet of Deddy Corbuzier's video conversion in religious belief is different, so it tends to generate different comments. This is based on the ability of citizens of the internet to understand video. At a more complex level, everyone has a different component of understanding. Different cultural backgrounds cannot be attributed to certain parties as a mistake. Naturally, someone understands based on an authentic culture that is understood from the start. This condition shows the level of mastery of insight that is different between each person. This gap ultimately makes each netizen have a different understanding according to their respective preferences.

\section{The Netizens Acceptance to Deddy Corbuzier's Conversion of Religious Beliefs on the Hotman Paris Show YouTube Channel}

Acceptance is crucial in the processed of attitude change [12]. In this research, the intended acceptance is the attitude of citizens of the internet to accept the decisions made by Deddy Corbuzier. Based on the research findings, citizens of the internet tend to accept and even welcome the religious changes made by Deddy with polite sentences and prayers to remain istikamah being a Muslim. Citizens of the internet also expressed their desire to become more obedient Muslims than before. This acceptance did not come from Muslim citizens of the internet only, but non-Muslims also accepted Deddy's decision. In some comments, citizens of the internet were also found without hesitation in writing down their hopes that they would soon follow Deddy to believe in Islam.

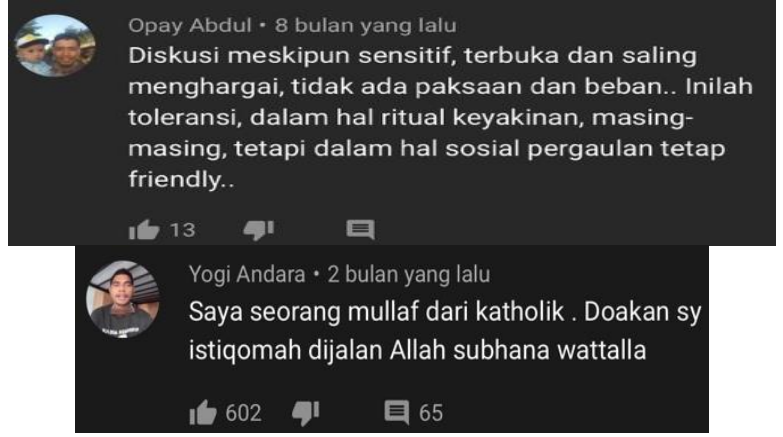

Fig. 7. Netizens proud to this talkshow and prayers to istakamah.

Based on this discussion, the presence of Deddy's conversion video on social media encourages citizens of the internet to respond in the form of acceptance of Deddy's decision. This acceptance indicates that the success of videos uploaded to YouTube is not just watched by citizens of the internet but understood and touched the feelings of citizens of the internet so that they accept Deddy's decision and give rise to the desire to become a better Muslim. According to Wodak [13] the power of those who can use language for their various vested interest. Acceptance that goes to the heart cannot be separated from the language factor because language is an important tool in preaching. Without using polite language, Deddy's statement regarding his decision to become a Muslim has the potential to lead citizens of the internet to think negatively about his former religion. Although negative comments are still found, positive comments tend to be dominant. The conversation conducted by Deddy and Hotman Paris was sensitive, but both were able to pack questions and answers in light sentences without discrediting the religion that Deddy previously believed.

\section{CONCLUSION}

Regarding this explanation, it can be concluded that citizens of the internet have various responses to Deddy Corbuzier's video clarifying religious conversion. Citizens of the internet pay attention in the form of like or dislike symbols and comments. Then the understanding received by citizens of the internet consists of positive, negative and neutral comments. The acceptance of citizens of the internet is the desire to change for the better, namely to be more obedient, istikomah, to become a convert and to accept Deddy Corbuzier's decision to convert. An interesting finding is that netizen comments related to the video triggered a comment war between citizens of the internet.

\section{ACKNOWLEDGMENT}

This research was supported by Universitas Samudra. We thank to all committee the international conference on science, technology, and modern society. We also would like to say thank you to all who have helped us in providing the data for this research. 


\section{REFERENCES}

[1] R. Nasrullah, Media Sosial Perspektif Komunikasi, Budaya dan Sosioteknologi, Bandung: Remaja Rosdakarya, 2017.

[2] W.A. Social, Digital in 2020, 2020. [Online]. Available: https://wearesocial.com/blog/2020/10/social-media-users-pass-the-4billion-mark-as-global-adoption-soars\#

[3] S. Siersdorfer, S. Chelaru, W. Nejdl, and J. San Pedro, "How useful are your comments?," Proceedings of the 19th international conference on World wide web - WWW '10, vol. 8, pp. 891-900, 2010.

[4] C.H. Hirschkind, "Experiments in Devotion Online: The Youtube Khutba," International Joural of Middle East Studies, vol. 44, no. 1, pp. 5-21, 2012.

[5] B. Bungin, Penelitian Kualitatif, Jakarta: Kencana, 2009.

[6] H. Haslin and H. Hamdzun, "Technology and Religion: Information Seeking Behaviour of Online Religious Information Among Malays," in IDOSI Publications, 2013.
[7] O.U. Effendy, Ilmu Teori dan Filsafat Komunikasi, Bandung: Citra Adira Bakti, 2009.

[8] F.I. Tanesab, I. Sembiring and H. Dwi Purnomo, "Sentiment Analysis Model Based On Youtube Comment Using Support Vector Machine," International Journal Of Computer Science Anf Software Engineering , vol. 6 , no. 8, pp. 180-185, 2017.

[9] K.E. Andersen, Introduction to Communication Theory and Practice, United States of America Company, inc, 1972.

[10] D.S. White and L.C. Alison, "Visitors and Residents: A new typology for online engagement," First Monday, 2011.

[11] A. Ahmadi, Psikologi Belajar, Jakarta: Rineka Cipta, 2013.

[12] K.J. Kaplan, "From Attitude Formation to Attitude Change: Acceptance and Impact as Cognitive Media," American Sociological Association, pp. 448-467, 1972.

[13] R. Wodak, "Language, power and identity," Language Teaching, vol. 45 , no. 2,2012 